\title{
A Proposal Framework for Investigating Website Success in the Context of E-banking: An Analytic Network Process (ANP) Approach
}

\author{
Mona Salehi ${ }^{1}$, Abbas Keramati $^{2}$ and Sina Elli ${ }^{3}$ \\ ${ }^{1}$ Lulea University of Technology, monaasalehi@gmail.com \\ ${ }^{2}$ University of Tehran, keramati@ut.ac.ir \\ ${ }^{3}$ Lulea University of Technology, sina.elli@gmail.com
}

\begin{abstract}
This study proposes a framework to investigate the factors that are influencing e-banking website success. Moreover, it is intended to define an approach to find out relative importance of website success factors in selecting the most preferred e-banking website by identifying relative importance of each success factors and priority of alternative websites across e-banking domains.

The emergence of electronic commerce during last decade, and lack of direct human interaction especially in service sectors such as banks, entails the use of each service element as an opportunity for web providers to reinforce or establish quality perceptions for customers [1]. In the e-commerce environment, full functional use of an e-commerce system should include informational use, transactional use, and customer service [2]. One of the highly cited IS Success models was updated by adding Service quality dimension to information and system quality measures in order to capture the essential characteristics being delivered to customers[3]. Updated Delone and McLean IS Success Model that can be adapted to the measurement challenges of the new e-commerce world is chosen as a framework to investigate e-banking website success factors.
\end{abstract}

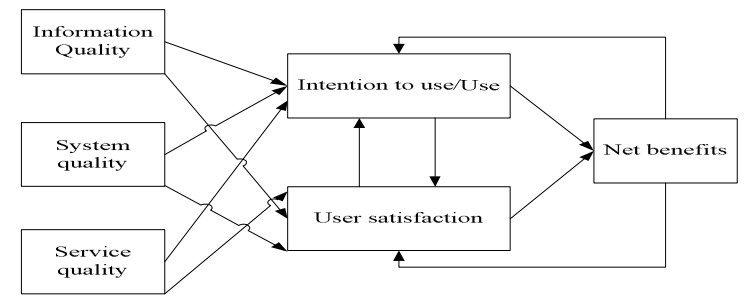

Figure1.The Updated Delone and McLean IS Success Model (2003) [1]

Finding out the relative importance of each variable in Updated Delone and McLean IS success model and ranking alternative websites is a complex decision which needs structures to represent demonstration of the flow of influences [4]. According to the updated Delone and
McLean IS success model, there are feedbacks between IS success variables, so that this model does not have specifying levels [3]. The ANP is a logical way to deal with dependency within the components of a structure, and that is the only tool which is capable to simplify and manage a complexity of a decision problem involving feedbacks [4]. As shown in figure 2, updated Delone and McLean IS success model (2003) is extended through Analytic Network Process (ANP) (2008) approach in this research article to reduce a multidimensional problem structure into a unidimensional one [4].

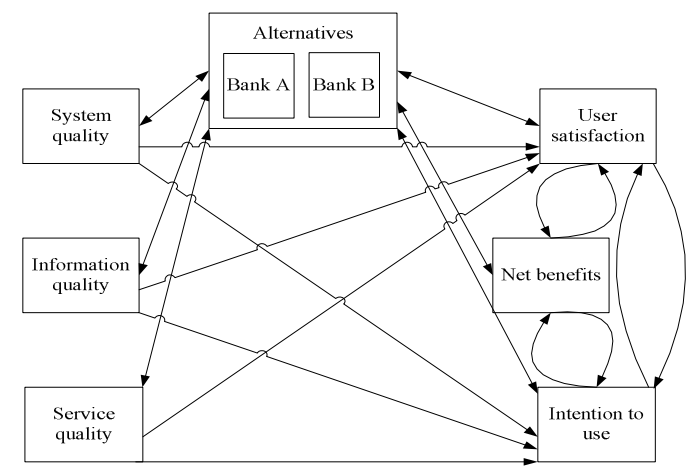

Figure2.Proposed framework

\section{References}

[1]. Broderick, AJ. and Vachirapornpuk, S., Service quality in internet banking: the importance of customer role. Marketing Intelligence \& Planning, 2002. 20(6): pp. 327-335.

[2]. Young, D., and Benamati, J., Differences in public web sites: The current state of large U.S. Firms. Journal of Electronic Commerce Research, 2000. 1(3): pp. 94-105.

[3]. Delone, WH. and McLean, ER., The Delone and McLean model of information systems success: a ten-year update. Journal of Management Information Systems, 2003. 19(4): pp. 9-30.

[4]. Saaty, T.L., Making decisions in hierarchic and network systems. International Journal of Decision Sciences. 2008. 1(1): pp. 24-78. 